\title{
Functional management of the economic activities of industrial systems
}

\author{
Elena Matveeva ${ }^{1, *}$, and Svetlana Simagina ${ }^{2}$ \\ ${ }^{1}$ Povolzhskiy State University of Telecommunication and Information, Department of Economic and Information Systems, 443010 \\ Samara, Russia \\ ${ }^{2}$ Samara University, Department of Mathematical Methods in the Economy, 443086 Samara, Russia
}

\begin{abstract}
This article refers to the methods of functional management of Industrial systems. In detail a management is examined at intershop level. An effective management is provided by the decision of operative economic and operational business tasks answering the decouplig of productive tasks to the workshops. Their permission is provided by realization of four base functions of management planning, control, adjusting, account. It is shown that qualificatory is a defining feature of planning. The methods of estimation and optimization of the batch, methods of estimation and remapping of the machine loading and workplace capacity, methods of simulation and optimization of the procedures are presented. For the exposure of rejections of productive process from the level set by planning, the tasks of account, control, analysis and adjusting are examined, that allows to warn possible deviations of actual motion of production from the expected model.
\end{abstract}

\section{Introduction}

The market demand rapid change and the integration to the World market result in the necessity to produce competitive products - both technically and costeffectively. This provides the prospect of the development of industrial systems. In market conditions the most effective industrial system should be adaptable to the permanent irregularity of the environment. This leads to the wide range of the product mix.

Convergence to meet the market requirements result in the expansive growth of the quantity of the short-run industrial systems which are managed by specific and complicated way, especially when we talk about major economical activities management.

The efficiency of the whole industrial system depends in tote on the business processes of all the phases and levels of major production management. The economical activities management is the process of specific decision-making on the ground of the stated objective, data collecting and processing, major business processes monitoring, and staff activities coordination [1].

\section{Main exposition}

The production business object management system is generally divided between the levels of inter-shop and inner-shop planning.

The production program for the shops subject to their specialization is developed at the inter-shop level. Relatively to the assembling the outrunning of the part launchings depends on the part manufacturing cycles, they can be estimated both for the different phases of production and for each part peculiarly [2].

The inner-shop management provides the solving of the operational problems in accordance with the decomposition of the shop production goals. The solving of those problems is provided by means of realization of the four basic management functions

$$
\sum_{i=1}^{n} \sum_{j=1}^{n}\left(P_{i j}+K_{i j}+Z_{i j}+U_{i j}\right)
$$

where $\mathrm{P}$ - planning, $\mathrm{K}$ - monitoring, $\mathrm{Z}$ - regulation, $U$ - record keeping, $i$ - processed parts, $j$ - procedures $[4,7]$.

The planning is the key function in the developed inner-shop management system, where the goal (planning period output) and the goal achievement mode (calendar timetable of the parts moving through workplaces) are specified. The decomposition of the operational problems, informatization and cybernation of basic business processes permit to overstep from process specialization to the higher level - specialization of the object locked sections (OLS). The OLS input data is the detailed plan generated as a result of solving of the operational planning problems at the inter-shop level. This plan assigns the OLS management goal [3].

For the realization of the OLS management functions the following tasks are stated and solved:

1. At the phase of planning. The optimal (providing balanced machine loading) batch sizes are estimated. Basing on that the machine loadings by type of procedure and by each workplace are estimated

\footnotetext{
*Corresponding author: helen matveeva@mail.ru
} 
according to the accepted specialization. The simulation of the parts processing is made;

2. At the phase of monitoring. The work shift goal achievement and the parts moving through workplaces are monitored. The interoperation stock volumes are reviewed;

3. At the phase of Regulation. Based on the actual accomplishment of the workplace shift goal and the deviation from the calendar timetable the work shift goals are revised for the next step of regulation;

4. At the phase of Record keeping. The actual accomplishment of the stated plans is identified. The collected data are used for the correction of the next planning period business process management $[4,5]$.

\section{Estimation and optimization of the batch sizes}

Estimation of the optimal batch sizes $-n_{\text {onm }}$ (estimated monthly) is a double critical task with minimizing of the combined losses from the disequilibrium between the required and the actual supply of the parts for the assembling shops $F\left(n, p_{1}\right)$, and between the costs determined by the laboriousness of the parts processing $T\left(n, p_{2}\right)$, wherein $p_{1}$ - the planned batch size $n_{n \pi}, p_{2}$ - the batch size minimum limit $n_{n p}$.

The particular efficiency indicators $F\left(n, p_{1}\right)$ and $T\left(n, p_{2}\right)$ determine the minimized function of function

$$
\hat{J}=\min _{n=n_{\text {onm }}}\left(F\left(n, p_{1}\right)+T\left(n, p_{2}\right)\right),
$$

where $\hat{J}$ - optimality criteria, and dictate the contradictory requirements to the batch size value.

Losses $F\left(n, p_{1}\right)$ from the disequilibrium $(\varepsilon)$ between the required (specified) $n_{3}$ and the actual supply $n_{\phi}$ $\varepsilon=n_{3}-n_{\phi}$ - directly depends on the batch size value $\frac{d F\left(n, p_{1}\right)}{d n}>0$. And, the smaller batch sizes should be formed based on the minimization of the losses $F(n)$. The laboriousness of the processing $T\left(n, p_{2}\right)$, contrary to the losses $F\left(n, p_{1}\right)$, is in inverse relation to the batch sizes $-\frac{d T\left(n, p_{2}\right)}{d n}<0$. When $n$ is low the costs of the machine tooling and the continuous correction of the plans increase significantly. And, the bigger batch sizes should be formed based on the minimization of the costs $T\left(n, p_{2}\right)$.

It is stated that:

1. The losses from the disequilibrium $F\left(n, n_{n л}\right)$ increase drastically when the planned supply is poorer than the required one $n_{n \pi}<n$;

2. Significant increase of the laboriousness arise from $n_{n p}>n$, as a result of the sharp increase of the machine tooling costs (amount of time and other resources) $[1,4]$.

Formalizing the developed regularities depending parametrically on $n_{n л}$ and $n_{n p}$, correspondingly, by the degree correlations for the sensitivity functions

$$
\begin{aligned}
& \left.\frac{d F\left(n, n_{n n}\right)}{d n}\right|_{n_{n i}<n}>>\left.\frac{d F\left(n, n_{n n}\right)}{d n}\right|_{n_{n i}>n} \\
& \left.\frac{d T\left(n, n_{n p}\right)}{d n}\right|_{n<n_{n p}}<<\left.\frac{d T\left(n, n_{n p}\right)}{d n}\right|_{n>n_{n p}}
\end{aligned}
$$

and, based on the analysis above, it is determined that the sensitivity of the laboriousness of the parts processing is higher than the losses from the production disequilibrium

$$
\left|\frac{d T\left(n, n_{n p}\right)}{d n}\right|>\frac{d F\left(n, n_{n \lambda}\right)}{d n}
$$

The asymptotic solution for the parameterized task of optimization is found as follows $n_{\text {onm }}=\sup \left\{n_{n л,} n_{n p}\right\}$ (Fig. 1)
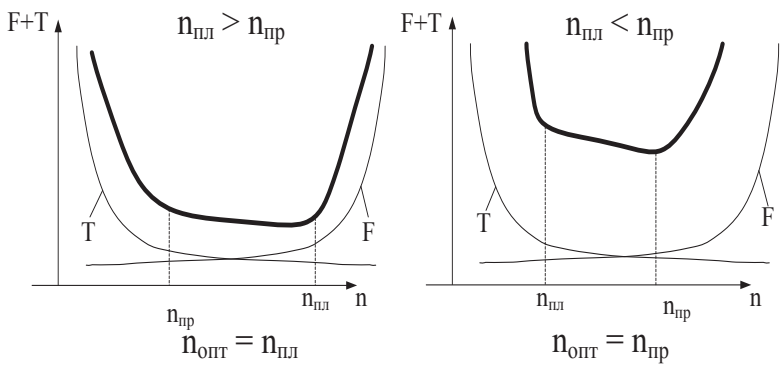

Fig. 1. Batch size optimality functional diagrams

Based on the solved task the batch size optimization is made for each part on each procedure reducing the machine tooling cases number to the minimum, subject to the reasonable workplace capacities and the assembling shop demands for the planned period. The comparison between the time for the machine tooling and the part processing period planned length is showed at Figure 2 for the five types of procedures, for the implemented method of the economical activities management, and for the developed optimization algorithm.

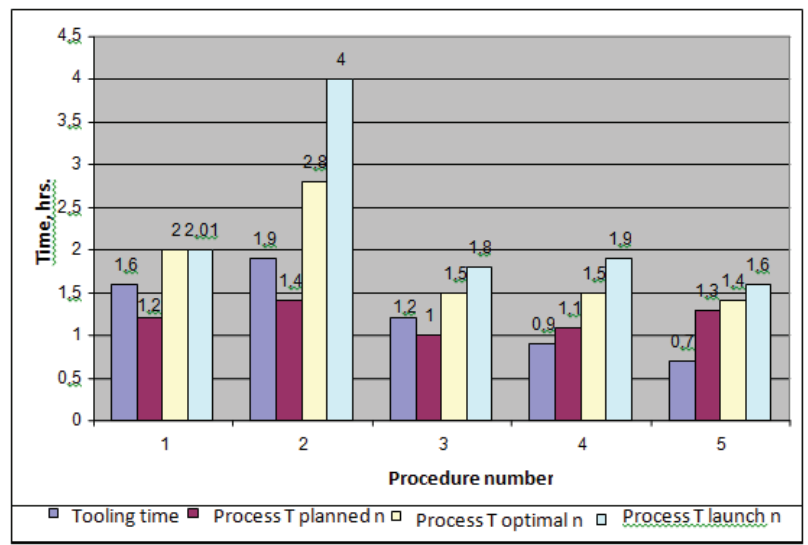

Fig. 2. Comparison of the machine tooling time and the batch processing length diagram

Based on the implementation of the developed algorithm the batches were formed with the processing times exceeding the machine tooling time by $20,1 \%$ at 
the first procedure and increasing up to by $56,1 \%$ through the fifth procedure. The reduced batch processing laboriousness went $37 \%$ down [1].

\section{Estimation and remapping of the machine loading and workplaces capacity}

The task of the optimization of the machine loading $\left(3 O_{i j}\right)$ is stated as minimization of the production plan tightness $\left(P_{i j}\right)$ and maximization of the workplaces $\left(P M_{i j}\right)$ when the production mix is numerous, and the production volume is unstable by months: $\left\{\begin{array}{l}\left(P_{i j}\right) \rightarrow \min \\ \left(P M_{i j}\right) \rightarrow \max \end{array}\right\} \mapsto 3 O_{i j}[1,5]$.

The solution of the laboriousness and machine loading factors estimation tasks is made by each type of work for the required production terms - year, month, week, etc. - for the whole enterprise $\left(B P_{i j}{ }^{3}\right)$, for the shops $\left(B P_{i j}{ }^{4}\right)$, for the production sections $\left(B P_{i j}^{I I 3 y}\right)$, for the workplaces $\left(B P_{i j}^{P M}\right) \cdot 3 O_{i j}=\sum_{k}^{12} B P_{i j}$.

$$
B P_{i j}=\left\{B P_{i j}^{3} ; B P_{i j}^{L} ; B P_{i j}^{\Pi 3 Y} ; B P_{i j}^{P M}\right\},
$$

where $k$-planned period (mon.).

Analysis of the real enterprises operation indicates the substantial irregularity of the machine loading and workplaces capacity.

The task of the minimization of the irregularity of the machine loading by the type of work and by the workplaces is formalized by the optimality functional

$$
\hat{J}=\min _{T O} \sum_{i} \sum_{j}\left|K_{i j}\left(T O_{a}\right)-K_{i j}^{\mu o p s}\right|,
$$

where $K_{i j}$ - machine loading factors $i$ - type of work, $j$ - workplace; $K_{i j}{ }^{\text {норм }}$ - loading standard; $\mathrm{TO}_{a}-$ $a=1,2,3 \ldots-$ type of work technological procedures set. $n \times m$

Factors $K_{i j}$ form the quadratic matrix with the size

$$
K=\left[\begin{array}{cccc}
K_{11} & K_{12} & \ldots & K_{1 m} \\
K_{21} & K_{22} & \ldots & K_{2 m} \\
\ldots & \ldots & \ldots & \ldots \\
K_{n 1} & K_{n 2} & \ldots & K_{n m}
\end{array}\right]
$$

where $n$ - machine types quantity; $m$ - workplaces number.

The exact solution of the optimization task corresponds the significant complication. For the solution of the task the approximate successive task decomposition is implemented.

For the first step, the machine loading factors are taken as variables for $n$ types of machines corresponding to the average workplaces capacity.

$$
K_{i}=\frac{1}{m} \sum_{j=1}^{m} K_{i j}, \quad i=1,2 \ldots n
$$

For the second step, $K_{i}$ - are estimated. For their determination the optimization task with functional is solved

$$
\hat{J}=\min _{T O} \sum_{i=1}^{n}\left|K_{i}\left(T O_{a}\right)-K_{i}^{\text {норм }}\right|
$$

For the third step, the similar task of the minimization of the irregularity of the workplaces with functional is solved for the estimated machine loadings

$$
\hat{J}=\min _{T O} \sum_{j=1}^{m}\left|K_{j}\left(T O_{a}\right)-K_{j}^{p}\right|
$$

The analysis and remapping of the loading is made in several steps

The comparison of the OLS machine loading diagrams is showed at Figure 3 by the types of work corresponding to the existing and the developed planning methods.

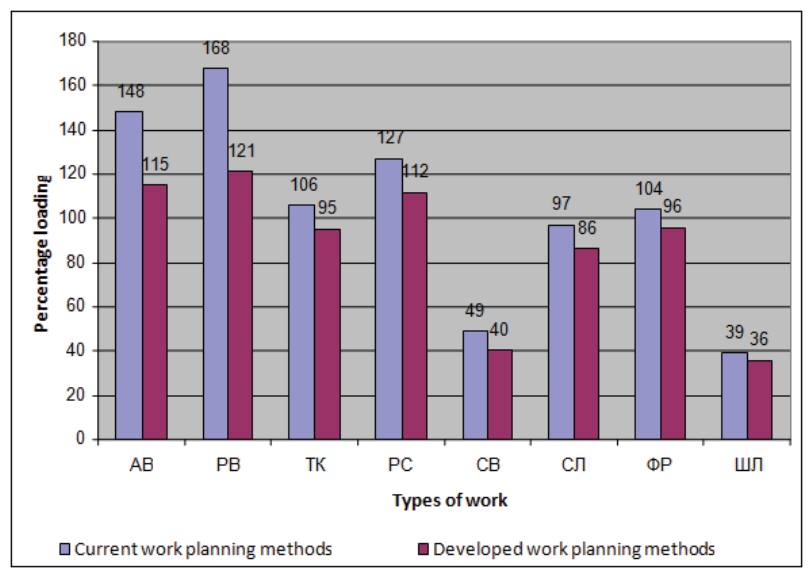

Fig. 3. Machine loading diagrams by the types of work for the different planning methods $(\mathrm{AB}$ - automatic machine, $\mathrm{PB}-$ capstan lathe, TK - turning lathe, PC - boring lathe, $\mathrm{CB}$ drilling lathe, СЛ - locksmith's, ФР - milling lathe, ШЛ grinding lathe)

The implementation of the developed work planning method permits to reduce the irregularity of the machine loading by 1,4 times from $33,5 \%$ to $24,4 \%$, to eliminate the overload of two technological procedures, and to reduce the overload of the rest of the works by 3,2 times $[1,4]$.

The comparison of similar actual and estimated capacity diagrams for the different workplaces is showed at Figure 4.

The implementation of the developed planning method reduces the irregularity of the capacity by 2,3 times down to $16 \%$, reduces the average overload of workplaces by 2,5 times from $49,3 \%$ to $20 \%$, and reduces the maximum overload by 3 times $[1,4]$.

The developed methods of reasonable loading by types of work and by workplaces could be implemented for the different calendar and planning periods. 


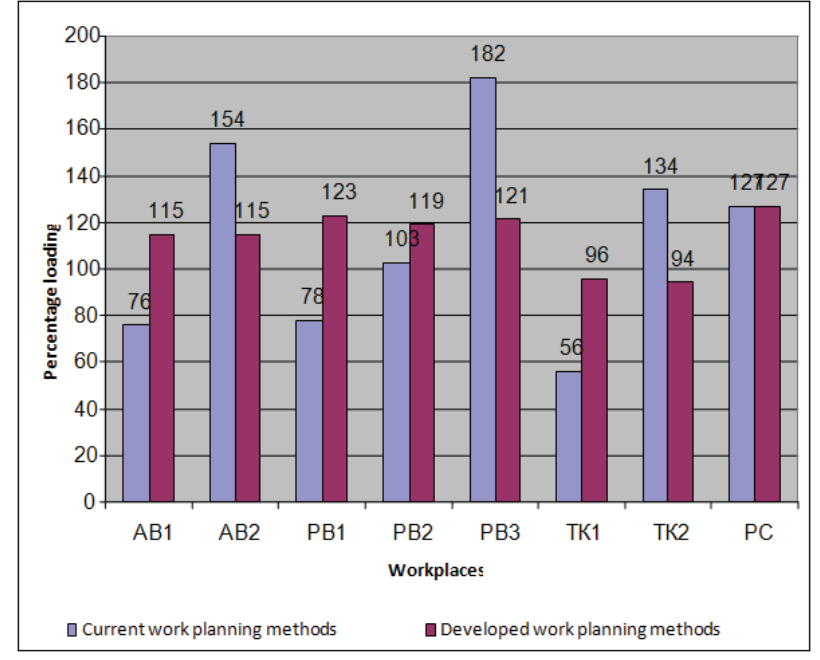

Fig. 4. Workplaces capacity diagram for the different planning methods

\section{Simulation of the production procedure}

The task of the improvement of planning stipulates the simulation of the parts movement through the workplaces of the OLS with the optimization of the processing order providing the in-time arrival to the assembling and the reasonable machine loading.

The minimization of the processing cycle duration $\left(T_{u}\right)$ is taken as optimization criteria.

$$
\left.T_{u j}=\sum_{j=1}^{m} a_{j}+t_{k} \cdot n\right] \rightarrow \min
$$

where $t_{\kappa}-$ all parts processing time at the last workplace ( $\mathrm{min}) ; a_{j}-$ drift of the beginning of the last procedure relative to the first one.

The solution of the task is possible with the implementation of the F.I. Paramonov's method based on the simulation of the phases of the parts processing business process. The basement of the forming of part processing simulator is the time of the outrunning of the part processing launchings at the interfacing workplaces. The optimization of the parts processing order is made by the minimum sum of differences between the processing times at the connected workplaces [6].

The solution is the production business process calendar timetable developed based on the equilibrium between the program goals and sizes of the batches launched into production at different shops, and on the coordination of the production terms at the interfacing business process phases $[4,6]$.

The fragment of the simulation of the parts A, Б, В, $\Gamma$, Д production process is showed at Figure 5.

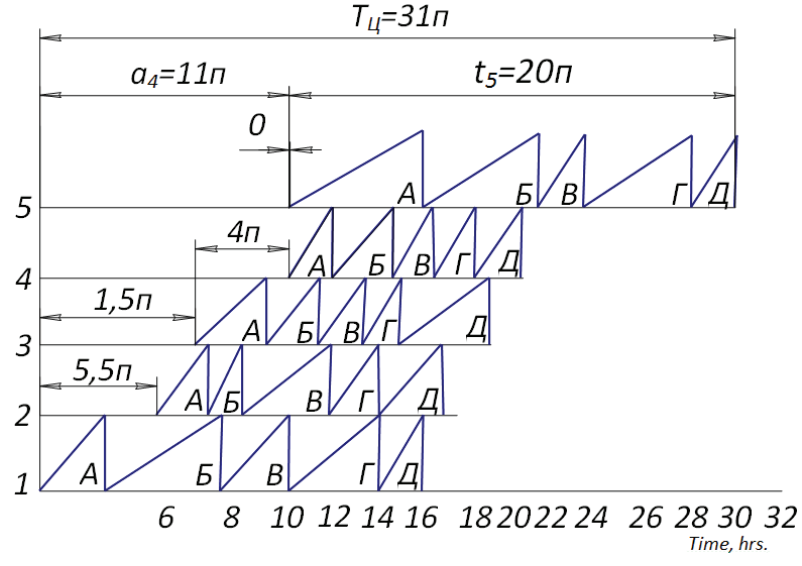

Fig. 5. The fragment of the simulation of the part A, Б, В, Г, Д batches processing.

The time movement of the processed parts is showed for the coupled workplaces $1,2,3,4,5$. The diagram determines the time of the outrunning of the work start at the first workplace of each couple. The time depends on the correlation between the processing times at the coupled workplaces.

The planned documents for the production section and for the workplaces are made as a result of the simulation. They are the production mix assignment, parts processing calendar time schedule by workplaces, machine loading schedule for the month.

\section{Record keeping, monitoring, analysis and regulation of the production}

For in-time detection of the production process deviations the tasks of record keeping $\left(\mathrm{U}_{\mathrm{i}}\right)$, monitoring $\left(\mathrm{K}_{\mathrm{i}}\right)$, analysis $\left(\mathrm{A}_{\mathrm{i}}\right)$ and regulation $\left(\mathrm{Z}_{\mathrm{i}}\right)$ are being solved.

The variety of the working shift goals at each production section and workplace, the variety of the batches, of the procedures, etc. are taken into account for the solution of those tasks.

The production regulation task is the decisionmaking on the operational elimination of the production process deviations. The following complex of the tasks is being solved at the phase of the regulation $Z_{\mathrm{i}}=\left\{a_{3 \mathrm{ij}}\right.$; $\left.\mathrm{r}_{\mathrm{ij}} ; \mathrm{n}_{\mathrm{ij}} ; \Delta n ; \mathrm{K}_{3 \mathrm{i}} ; \mathrm{T}_{\text {доп }} ; T_{\Sigma}\right\}$ : analysis of the dayshift assignment actual achievement for the past step of the regulation $\left(\mathrm{a}_{3 \mathrm{ij}}\right)$, decision-making for the necessity of the including of the unaccomplished items to the next step of the regulation $\left(\mathrm{r}_{\mathrm{ij}}\right)$, Launched batches and additional batches laboriousness estimation $\left(\mathrm{n}_{\mathrm{ij}}\right)$, determination of the times of launching ( $\Delta n)$ next step machine loading estimation $\left(\mathrm{K}_{3 \mathrm{i}}\right)$, - analysis and correction of the machine loading $\left(\mathrm{T}_{\text {доп }}\right)$, working out the dayshift assignments $\left(T_{\Sigma}\right)$ for the next step of the regulation [7].

The tasks of the record keeping are the collecting of the daily information upon parts availability at the interoperation stock. Based on that the achievement of the dayshift and production mix assignments is analyzed, and the necessity of the correction of the planned 
assignments for the next step of the regulation is determined.

\section{Conclusion}

The organization of the works at the OLS should be addressed to the prevention of the possible deviations of the actual production from the estimated simulator, to the maximum possible maintenance of the launchingoutput times order for each batch by the procedures. This is provided by the following conditions:

1. Strict regulation of the functional links and circulation of documents between the departments of the shop and whole factory;

2. Workplaces planned-prophylactic service system;

3. Specially developed methods of the monetary and moral incentives for the achievement of the dayshift and month assignments $[4,8]$.

The problem of the improvement of the day-to-day management system should be solved integrally with the implementation of the modern means and methods of the business system, what management efficiency allows to promote by economic activity of the productive systems.

\section{References}

1. A.C. Ivanova, V.V. Pirogov, C.N. Polotovskiy and E.A. Matveeva, Integrated manufacturing and control systems for machine-building enterprises (Samara, OOO AC-Gard Publ., 2011)

2. A.N. Troshin, Automatic manufacture control system for machine-building enterprise (Moscow, Statistika Publ., 1978)

3. J.V. Adayev, Short-term team production planning (Penza, Penz. Politekhn. Inst. Publ., 1983)

4. E.A. Matveeva, Best management practice in job lot production, Computer and information technologies bulletin, no. 2, pp. 29-37 (2007)

5. E. Matveeva, S. Simagina, Manufacturing process Optimization at Enterprises, Key engineering materials, vol. 684, pp. 409-413 (2016)

6. F.I. Paramonov, Manufacturing processes simulation (Moscow, Mashinostroyeniye Publ., 1984)

7. E.A. Matveeva, Development of generic integrated enterprise resource planning systems for various branches of industry, Intelligence, Innovation, Investments. Proc. Int. Forum "Russia as emerging society: economy, culture, management, pp. 30-35. (2011)

8. E.A. Matveeva, Implementation and economic performance indices model of integrated enterprise resource planning systems, Samara State Universuty of Economics bulletin, no. 6(80), pp. 44-50 (2011) 